\title{
Recent insights into cigarette smoking as a lifestyle risk factor for breast cancer
}

\author{
This article was published in the following Dove Press journal: \\ Breast Cancer - Targets and Therapy \\ 7 March 2017 \\ Number of times this article has been viewed
}

\section{Shannon Kispert Jane McHowat}

Department of Pathology, Saint Louis University School of Medicine,

St. Louis, MO, USA
Correspondence: Jane McHowat Department of Pathology, Saint Louis University School of Medicine, 1402 S Grand Blvd, St. Louis, MO 63104, USA Tel + I 3 I4 9779295

Email mchowaj@slu.edu
Abstract: There have been many cohort studies published reviewing the epidemiological evidence that links breast cancer to cigarette smoking, yet the underlying mechanisms are largely unknown and research studies are few and incomplete. Although cohort studies are important in establishing a connection between breast cancer and cigarette smoking, basic science research is necessary to prove the relationship and to highlight potential interventions and drug targets that can be used to manage the disease. This subject has been controversial for many decades; however, there has been a recent resurgence in interest because of the widespread acknowledgment of the role lifestyle choices play in cancer development and progression. This review will detail the current statistics associated with cigarette smoking and discuss recent cohort and basic research studies that highlight the association of cigarette smoking and breast cancer initiation and progression.

Keywords: metastasis, tobacco, tumor growth

\section{Cigarette smoking: still an epidemic}

Cigarette smoking is associated with increased morbidity and mortality around the world and remains a prevalent lifestyle choice, despite aggressive antismoking campaigns in recent years. Approximately $16 \%$ of all US adults are classified as smokers. ${ }^{1,2}$ As such, tobacco use remains the single largest preventable cause of death and disease in the USA. ${ }^{1}$ According to the Center for Disease Control, smoking leads to nearly half a million premature deaths and the loss of over 5 million years of potential life in both children and adults. ${ }^{2,3}$

Despite a general decline during the past three decades, year-to-year decreases in prevalence have been seen only intermittently recently. ${ }^{1,4}$ In contrast to the USA, tobacco consumption rates are rising in the developing world, with the greatest amount of smokers in the western Pacific. ${ }^{5}$ There are $\sim 1.1$ billion smokers worldwide, and $80 \%$ of these smokers live in low- and middle-income countries, making this a worldwide epidemic. ${ }^{5}$ Globally, smoking leads to 6 million deaths a year, with over 600,000 of those deaths attributed to secondhand smoke. ${ }^{5}$

In the USA, smoking is prevalent among American Indians (29\%), whites (18\%), and blacks $(18 \%) .{ }^{2}$ Cigarette smoking is least prevalent in persons with undergraduate $(8 \%)$ and graduate degrees $(5 \%)$ and highest among those individuals with general education diplomas $(43 \%) .^{2}$ Poverty status is closely tied to education status; thus, it is not surprising that cigarette smoking was highest in individuals living below the poverty line $(26 \%)$ versus those who live at or above the poverty line $(15 \%){ }^{2}$ 
Smoking-related illness costs $>\$ 300$ billion a year in the USA alone. ${ }^{1}$ This includes nearly $\$ 170$ billion in direct medical care for adults and $\$ 156$ billion in lost productivity. ${ }^{3}$ Despite the toll of cigarette smoking on both public health and the economy, the tobacco industry is booming; 15 billion cigarettes are sold in the world daily. Efforts to reduce smoking include bans of advertisement, picture warnings, restrictions on sales to minors, and taxation. Most countries have minimal to zero restrictions on tobacco advertising; only 29 countries have a complete ban in place. ${ }^{5}$ Tobacco excise tax is the most effective control for tobacco usage, as it targets populations with lower socioeconomic status who make up the highest group of smokers. Despite the efficacy of taxation, few countries have a tobacco tax substantial enough to affect tobacco consumption. ${ }^{5}$

\section{Cellular response to toxins in cigarette smoke}

More than 16 million Americans live with a smoking-related disease. ${ }^{5}$ The toxins in cigarette smoke have access to almost every organ of the body; thus, smokers are more likely than nonsmokers to develop a wide range of diseases, including heart disease, stroke, pulmonary disease, and cancer. ${ }^{1}$ Smoking has been linked to numerous cancers including those of the lung, kidney, pancreas, colon, bladder, larynx, and esophagus. ${ }^{5}$

Tumorigenesis requires the repeated use of cigarettes, which is easily achieved by the vast majority of active smokers because of the addictive nature of nicotine. ${ }^{6}$ The subsequent dangers of cigarette smoking arise from the $\sim 70$ carcinogenic materials out of the total 7,000 chemicals in cigarettes. Perhaps the most notable and studied carcinogens include polycyclic aromatic hydrocarbons and tobaccospecific nitrosamines. ${ }^{6}$ These carcinogens are metabolically activated and result in the production of DNA adducts, which can evade cellular repair mechanisms, allowing for replication of permanent mutations. ${ }^{6}$ Human cancer mutation signatures have been identified that correlate with tobacco smoking and are likely caused by polycyclic hydrocarbons and subsequent DNA adduct production. ${ }^{7}$ In addition, tobacco carcinogen-derived mutations have been associated with several oncogenes, such as Ki-ras2 Kirsten rat sarcoma viral oncogene homolog, and tumor suppressor genes like p53.,9 This mechanism continues to be studied in human lung cancer, but it is largely unexplored in other cancers.

\section{Effects of cigarette smoke on cancer cells and established tumors}

Many studies have looked at the effects of cigarette smoking on tumorigenesis, yet very little research has investigated the effects of cigarette smoking in cancer patients. ${ }^{10} \mathrm{~A}$ recent Surgeon General's report associated cancer patients who smoke with higher rates of recurrence. ${ }^{1}$ The report also claimed increased risk of secondary cancers and mortality rates for smokers. ${ }^{1}$ Several studies have looked at the impact of cigarette smoke on cell proliferation in cancer cells. Increased cell proliferation following cigarette smoke component exposure has been seen in esophageal, breast, and lung cancer cells. ${ }^{11,12}$ In addition to cell proliferation, cigarette smoke can induce migration in cancer cells, a hallmark of tumor progression. ${ }^{13}$ Incubation with cigarette components results in increased cell migration in several human cell lines, including colon, prostate, gastric, breast, and ovarian cancer cells. ${ }^{14-18}$

Immunomodulation has also been affected by cigarette smoke exposure to cancer cells. Nuclear factor-kappa B (NF- $\mathrm{kB}$ ) serves as a regulator of genes involved in immune responses, such as cytokines, and those involved in cell survival. ${ }^{19}$ Total particulate matter from cigarettes induced the activation of NF- $\mathrm{KB}$ in human histiocytic lymphoma, epithelial adenocarcinoma, non-small cell lung carcinoma, and head and neck squamous cell carcinoma. ${ }^{20}$

The negative effects of cigarette smoke on cancer cells have serious implications for cancer patients undergoing treatment. Smoking throughout treatment is associated with increased mortality and treatment-related complications. ${ }^{21}$ Peppone et al found that smokers undergoing cancer treatment had a higher total symptom burden when compared with nonsmokers. ${ }^{21}$ This study also showed that smoking cessation before treatment resulted in a lower total symptom burden comparable to nonsmokers. ${ }^{21}$ Follow-up studies have shown that breast cancer survivors who continue to smoke have a 2.2-fold increased risk of contralateral breast cancer among breast cancer survivors, suggesting that smoking cessation would be beneficial. ${ }^{22}$ An ongoing clinical trial is evaluating the efficacy of smoking cessation intervention among cancer patients, including breast cancer, and investigating its effects on quality of life and symptoms. ${ }^{23}$

\section{The association between smoking and breast cancer}

Breast cancer is the second most commonly diagnosed cancer and is the second leading cause of cancer mortality among women. ${ }^{24}$ The Surveillance, Epidemiology, and End Results Program (SEER) of the National Cancer Institute (NCI) estimates 246,660 new breast cancer cases in 2016, representing $14 \%$ of all new cancer cases. Although primarily a disease in women, in 2013, the Centers for Disease Control and Prevention (CDC) reported 2,000 new breast cancer 
diagnoses in men and 400 deaths. It is not surprising then, that the lifetime risk of developing breast cancer for women is $12.4 \%$. According to the $\mathrm{CDC}$, known risk factors include age, family history of breast cancer, obesity, alcohol use, and genetic mutations such as BRCA1/2, dense breast tissue, oral contraceptive use, and combination hormone therapy use.

Ductal carcinoma in situ is the most common histopathological type of breast cancer. ${ }^{25}$ Invasive ductal carcinoma can then metastasize from the primary site, most commonly to the bone, lung, and liver. ${ }^{26}$ Metastatic cancers account for the majority of cancer deaths rather than the primary tumor formation. ${ }^{27}$ According to the NCI's SEER program, $\sim 6 \%$ of patients already have metastatic disease by the time of first diagnosis, which makes treatment challenging and clinical management of metastasis imperative. ${ }^{28}$

\section{Breast cancer and smoking: evidence for a direct link Cohort studies}

The association between breast cancer and smoking has been controversial. Several cohort studies published in the 1990s found little evidence for increased breast cancer risk and reviews of studies published in the early 2000s stated that the association was unclear. ${ }^{1,29,30}$ In 2009, the Canadian Expert Panel on Tobacco Smoke and Breast Cancer Risk concluded that active smoking and breast cancer is consistent with causality. ${ }^{31}$ The same panel also concluded consistent causality between secondhand smoke exposure and premenopausal breast cancer. ${ }^{31}$ In addition, the International Agency for Research on Cancer (IARC) met to reassess the effects of tobacco smoke on several cancers, reviewing over 150 epidemiological studies, and concluded that evidence exists, although limited, for tobacco smoke carcinogenicity in breast cancer. ${ }^{32}$

A recent cohort study by Luo et al found a $9 \%$ increased risk of breast cancer between former smokers and nonsmokers. This risk was even greater at $16 \%$ for current smokers. ${ }^{33}$ In addition to considering smoking alone, several cohort studies have identified risk factors involving specific habits of cigarette smoking, which include duration of smoking, number of cigarettes smoked, age at initiation, and years of cessation. Xue et al found breast cancer incidence to be elevated in ever smokers versus never smokers (hazard ratio [HR] 1.07, 95\% confidence interval [CI]) when adjusted for several factors, including age, family history, menarche age, body mass index, oral contraceptive use, history of benign breast disease, alcohol consumption, passive smoking, and age at first birth. However, the study reported comparable
HRs between past and current smokers (HR 1.09 versus 1.06, 95\% CI), suggesting that cessation had little effect following long-term smoking. ${ }^{34} \mathrm{~A}$ slight increase in incidence was seen with every increase of 20 pack-years, and increased HR for duration, quantity, and start age of smoking. ${ }^{34}$ The HR was elevated for those women who smoked 25 or more cigarettes a day (HR 1.14, 95\% CI), smoked 20 years or longer (HR $1.07,95 \% \mathrm{CI})$, and/or started smoking at or before 17 years of age (HR $1.07,95 \% \mathrm{CI}) .{ }^{34}$ In support, another recent study showed that smoking 40 or more cigarettes per day had the strongest association with the risk of breast cancer (HR $1.17,95 \%$ CI $).{ }^{35}$ According to the Surgeon General's report, the meta-analysis of 22 cohort and case-control studies did not provide a definitive answer as to whether smoking at a younger age provides a greater risk than developing the habit at older age. ${ }^{1}$ However, a recent pooled analysis by Gaudet et al, which included 934,681 participants, concluded that there was an $18 \%$ higher risk of breast cancer for women who smoked for $>10$ years before first birth. ${ }^{35}$

Several studies have investigated at patients who have already developed breast cancer. Pierce et al found that breast cancer patients who were former smokers with more than a 30 pack-year history had a 37\% increased risk of breast cancer recurrence and 54\% increased risk of overall breast cancer mortality when compared with nonsmoking patients. ${ }^{36}$ Overall mortality from any cause was increased by $60 \%$ for these heavy smokers. ${ }^{36}$

In addition to active smoking, several studies have looked at passive smoking. A report by IARC in 2004 stated that passive smoke (secondhand smoke) contains higher levels of several carcinogens, including benzene, formaldehyde, and N-nitrosamines. ${ }^{37}$ The European Prospective Investigation into Cancer and Nutrition that conducted the largest cohort analysis on smoking and breast cancer to date found higher risk of breast cancer for women who were former and current smokers, and who were currently exposed to passive smoking when compared with never smokers and those who were unexposed to passive smoking. ${ }^{38}$

Despite the results from numerous cohort studies, there are several confounding factors that have contributed to the controversial standing on cigarette smoking and breast cancer. ${ }^{37,39}$ Alcohol consumption, an identified risk factor for breast cancer, is positively correlated with cigarette smoking. Studies have tried to control for this compounding factor, yet problems with self-reported alcohol use have provided discrepancies and unreliable results. ${ }^{39}$ Other factors include mammography screening, which few studies have controlled for. Higher screening rates exist for nonsmokers and former 
smokers than current active smokers. Hence, incidence reporting may be biased because of possible undetected cancers in a large number of unscreened active smokers. ${ }^{39,40}$ Smoking may not only affect incidence rates but also affect the survival of patients with a previously established breast cancer, thus adding to the complication of these studies. ${ }^{39}$

\section{Laboratory studies}

While less basic science research has been performed, the results from laboratory studies provide a compelling case for the role of cigarette smoke-mediated breast cancer development and progression. The most notable starting point for the basis of these studies was to discover if cigarette smoke components reach the breast tissue. Components of cigarette smoke have been found in the nipple aspirate of female smokers. ${ }^{41}$ In addition, the presence of smoking-related DNA adducts in epithelial cells of breast milk demonstrate that cigarette components access breast tissue. ${ }^{41,42}$ Several mechanisms have been proposed for the development of cigarette smokeinduced breast cancer. Carcinogens found in cigarette smoke have caused mammary tumors in rodents, including Benzo[ $a]$ pyrene, isoprene, and ethylene oxide. ${ }^{43}$ The formation of DNA adducts has been proven to be a widespread mechanism for tumor development as a result of cigarette smoking. ${ }^{6}$

Smoking-induced mechanisms underlying tumor progression and metastasis have also been reported. Important studies have identified increased motility and epithelialto-mesenchymal transition (EMT) in breast tumor cells exposed to cigarette smoke. ${ }^{11,15,44}$ Di Cello et al showed that both normal mammary and breast cancer cells acquired fibroblastoid morphology when exposed to cigarette smoke. ${ }^{44}$ When cigarette smoke extract (CSE)-treated normal mammary epithelial cells were introduced into mice, they demonstrated better survival and colonization of mammary ducts. ${ }^{44} \mathrm{CSE}$-treated MCF-7 breast tumor cells were injected into the mammary pad of mice, and metastasis was seen in the lung of all mice versus no metastasis in mice injected with untreated MCF-7 cells, suggesting that cigarette smoke promotes invasion. ${ }^{44}$ The EMT process involves the loss of tumor cell adhesion from the basement membrane and enhancement of the invasive and migratory capabilities of tumor cells. ${ }^{45}$ Dasgupta et al reported alterations in several EMT markers when MCF-7 and MDA-MB-468 breast cancer cells were incubated with nicotine. Epithelial markers, such as E-cadherin and B-catenin, were decreased upon nicotine exposure, whereas mesenchymal markers, such as fibronectin and vimentin, were increased. ${ }^{11}$ We showed increased cell motility in MDA-MB-231 breast cancer cells exposed to CSE, which could be abrogated by inhibition of calcium-independent phospholipase $\mathrm{A}_{2}$ ( $\mathrm{iPLA}_{2}$ ), a precursor of platelet-activating factor (PAF). ${ }^{15} \mathrm{CSE}$ treatment also resulted in increased PAF and PAF receptor (PAF-R) expression. ${ }^{15}$ CSE-treated MDA-MB-231 cells were added to human lung microvascular endothelial cells (HMVECL) exhibited increased cell adherence when compared with untreated cells. ${ }^{46}$ The increased cell adherence could be abrogated by pretreatment with (S)-bromoenol lactone ((S)-BEL, an iPLA ${ }_{2} \beta$ inhibitor) and Ginkgolide B, a PAF-R antagonist. ${ }^{46}$ These studies suggest that cigarette smoke induces cell motility and increased cell adhesion, which could be, in part, due to PAF accumulation and increased PAF-R expression.

In addition to breast cell-based studies, several groups have identified gene polymorphisms that may contribute to breast cancer development and mortality. Slattery et al examined genes in the Janus kinase (JAK)/signal transducer and activator of transcription (STAT)/suppressor of cytokine signaling (SOCS) signaling pathways, which are involved in immune function and cell proliferation and have been implicated in various cancers. Their study found that several single-nucleotide polymorphisms in JAK2, STAT4, and SOCS2 interacted with cigarette smoking status to alter breast cancer mortality. ${ }^{47}$ Several groups have investigated gene polymorphisms in $\mathrm{N}$-acetyltransferase 2 (NAT2). ${ }^{48-50}$ NAT2 is an important enzyme responsible for the metabolic activity of aryl and heterocyclic amines, both found in cigarette smoke and capable of initiating carcinogenesis. ${ }^{51}$ Kasajova et al discovered NAT2 gene polymorphisms associated with long-term smokers, which could potentially predict breast cancer development in women. ${ }^{48}$

\section{Future directions}

Despite recent interest in cigarette smoke-mediated breast cancer, cohort studies have provided complicated results, and basic laboratory studies are still underway. Variations in smoker's lifestyles, including number of pack years, age of initiation, preexisting conditions, alcohol use, and genetic differences, have all contributed to complications when performing human studies. In addition, very few animal studies have been conducted because of the long-term cigarette smoke exposure required, yet these studies would provide novel insight into mechanisms that may lead to breast tumor initiation. Future research should aim at in vivo studies that could account for the large pack-year history required for cigarette smoke-derived breast tumorigenesis, metastasis, and mortality as well as control for variations in lifestyle habits. 


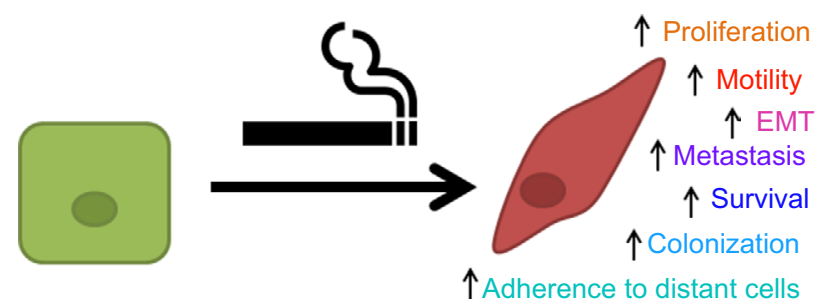

Figure I Cigarette smoke extract induced changes in breast epithelial cells. Abbreviation: EMT, epithelial-to-mesenchymal transition.

In summary, it is reasonable to conclude that long-term cigarette smoking provides a clear risk for breast cancer and worsened disease. Several cohort studies have shown that longer duration, increased amount, and beginning age of smoking are associated with high risk of breast cancer. Laboratory research has shown the effect of cigarette smoke components on normal mammary epithelial cells, which include increased motility, survival, colonization, and transition to mesenchymal phenotype (Figure 1).

Pretreatment of breast cancer cells with CSE has resulted in increased motility, adherence, and mesenchymal markers. Studies in human smokers have identified gene polymorphisms such as NAT2, which may confer higher risk of breast cancer. Overall, cigarette smoke can be considered an important risk factor for breast cancer development and progression. Future studies should aim at further elucidating the biochemical pathway for which these pathologies occur.

\section{Disclosure}

The authors report no conflicts of interest in this work.

\section{References}

1. Centers for Disease Control and Prevention (USA).The health consequences of smoking-50 years of progress: a report of the surgeon general. Rockville, MD: U.S. Department of Health and Human Services, Public Health Service, Office of the Surgeon General, 2014.

2. Jamal A, Homa DM, O'Connor E, et al. Current cigarette smoking among adults-United States, 2005-2014. MMWR Morb Mortal Wkly Rep. 2015;64(44):1233-1240.

3. Xu X, Bishop EE, Kennedy SM, Simpson SA, Pechacek TF. Annual healthcare spending attributable to cigarette smoking: an update. Am J Prev Med. 2015;48(3):326-333.

4. Agaku IT, King BA, Dube SR. Current cigarette smoking among adults-United States, 2005-2012. MMWR Morb Mortal Wkly Rep. 2014; 63(2):29-34

5. Centers for Disease Control and Prevention. Smoking and Tobacco Use. U.S. Department of Health and Human Services, Centers for Disease Control and Prevention, National Center for Chronic Disease Prevention and Health Promotion, Office on Smoking and Health, Atlanta, GA, 2016.

6. Hecht SS. Tobacco smoke carcinogens and lung cancer. J Natl Cancer Inst. 1999;91(14):1194-1210.

7. Alexandrov LB, Nik-Zainal S, Wedge DC, et al. Signatures of mutational processes in human cancer. Nature. 2013;500(7463):415-421.
8. Tang MS, Zheng JB, Denissenko MF, Pfeifer GP, Zheng Y. Use of UVABC nuclease to quantify benzo[a]pyrene diol epoxide-DNA adduct formation at methylated versus unmethylated $\mathrm{CpG}$ sites in the p53 gene. Carcinogenesis. 1999;20(6):1085-1089.

9. Feng Z, Hu W, Chen JX, et al. Preferential DNA damage and poor repair determine ras gene mutational hotspot in human cancer. J Natl Cancer Inst. 2002;94:1527-1536.

10. Sobus SL, Warren GW. The biologic effects of cigarette smoke on cancer cells. Cancer. 2014;120(23):3617-3626.

11. Dasgupta P, Rizwani W, Pillai S, et al. Nicotine induces cell proliferation, invasion and epithelial-mesenchymal transition in a variety of human cancer cell lines. Int J Cancer. 2009;124(1):36-45.

12. Li P, Wu WK, Wong HP, Zhang ST, Yu L, Cho CH. Chloroform extract of cigarette smoke induces proliferation of human esophageal squamouscell carcinoma cells: modulation by beta-adrenoceptors. Drug Chem Toxicol. 2009;32(3):175-181.

13. Hanahan D, Weinberg RA. Hallmarks of cancer: the next generation. Cell. 2011;144(5):646-674.

14. Jeon SY, Go RE, Heo JR, Kim CW, Hwang KA, Choi KC. Effects of cigarette smoke extracts on the progression and metastasis of human ovarian cancer cells via regulating epithelial-mesenchymal transition. Reprod Toxicol. 2016;65:1-10.

15. Kispert S, Marentette J, McHowat J. Cigarette smoke induces cell motility via platelet-activating factor accumulation in breast cancer cells: a potential mechanism for metastatic disease. Physiol Rep. 2015; 3(3):e12318.

16. Lien YC, Wang W, Kuo LJ, et al. Nicotine promotes cell migration through alpha7 nicotinic acetylcholine receptor in gastric cancer cells. Ann Surg Oncol. 2011;18(9):2671-2679.

17. Kim CW, Go RE, Lee HM, et al. Cigarette smoke extracts induced the colon cancer migration via regulating epithelial mesenchymal transition and metastatic genes in human colon cancer cells. Environ Toxicol. 2016;32(2):690-704.

18. Yang S, Long M, Tachado SD, Seng S. Cigarette smoke modulates PC3 prostate cancer cell migration by altering adhesion molecules and the extracellular matrix. Mol Med Rep. 2015;12(5):6990-6996.

19. Hayden MS, West AP, Ghosh S. NF-kappaB and the immune response. Oncogene. 2006;25(51):6758-6780.

20. Anto RJ, Mukhopadhyay A, Shishodia S, Gairola CG, Aggarwal BB. Cigarette smoke condensate activates nuclear transcription factorkappaB through phosphorylation and degradation of IkappaB(alpha): correlation with induction of cyclooxygenase-2. Carcinogenesis. 2002;23(9):1511-1518.

21. Peppone LJ, Mustian KM, Morrow GR, et al. The effect of cigarette smoking on cancer treatment-related side effects. Oncologist. 2011; 16(12):1784-1792.

22. Li CI, Daling JR, Porter PL, Tang MT, Malone KE. Relationship between potentially modifiable lifestyle factors and risk of second primary contralateral breast cancer among women diagnosed with estrogen receptorpositive invasive breast cancer. J Clin Oncol. 2009;27:5312-5318.

23. National Institutes Health; Wake Forest University. Feasibility of delivering a quitline based smoking cessation intervention in cancer patients. In: ClinicalTrials.gov. Bethesda, MD, USA: National Library of Medicine. 2015. Available from: https://clinicaltrials.gov/ct2/show/study/NCT01434342 NLM Identifier: NCT01434342. Accessed February 2, 2017.

24. Siegel R, Naishadham D, Jemal A. Cancer statistics, 2013. CA Cancer J Clin. 2013;63(1):11-30.

25. Weigelt B, Peterse JL, van 't Veer LJ. Breast cancer metastasis: markers and models. Nat Rev Cancer. 2005;5(8):591-602.

26. Lee YT. Breast carcinoma: pattern of metastasis at autopsy. J Surg Oncol. 1983;23(3):175-180.

27. Hunter KW, Crawford NP, Alsarraj J. Mechanisms of metastasis. Breast Cancer Res. 2008;10(Suppl 1):S2.

28. SEER cancer statistics review, 1975-2012. National Cancer Institute, Bethesda, MD, USA: National Cancer Institute; 2015. Available from: http://seer.cancer.gov/archive/csr/1975_2012/. Accessed November 2014. Accessed November 5, 2016. 
29. Palmer JR, Rosenberg L. Cigarette smoking and the risk of breast cancer. Epidemiol Rev. 1993;15(1):145-156.

30. Terry PD, Rohan TE. Cigarette smoking and the risk of breast cancer in women: a review of the literature. Cancer Epidemiol Biomarkers Prev. 2002;11(10 Pt 1):953-971.

31. Johnson KC, Miller AB, Collishaw NE, et al. Active smoking and secondhand smoke increase breast cancer risk: the report of the Canadian expert panel on tobacco smoke and breast cancer risk (2009). Tob Control. 2011;20(1):e2.

32. Secretan B, Straif K, Baan R, et al; WHO International Agency for Research on Cancer Monograph Working Group. A review of human carcinogens-Part E: tobacco, areca nut, alcohol, coal smoke, and salted fish. Lancet Oncol. 2009;10(11):1033-1034.

33. Luo J, Margolis KL, Wactawski-Wende J, et al. Association of active and passive smoking with risk of breast cancer among postmenopausal women: a prospective cohort study. BMJ. 2011;342:d1016.

34. Xue F, Willett WC, Rosner BA, Hankinson SE, Michels KB. Cigarette smoking and the incidence of breast cancer. Arch Intern Med. 2011; 171(2):125-133.

35. Gaudet MM, Carter BD, Brinton LA, et al. Pooled analysis of active cigarette smoking and invasive breast cancer risk in 14 cohort studies. Int J Epidemiol. Epub 2016 Dec 28.

36. Pierce JP, Patterson RE, Senger CM, et al. Lifetime cigarette smoking and breast cancer prognosis in the after breast cancer pooling project. J Natl Cancer Inst. 2014;106(1):djt359.

37. IARC. IARC Monographs on the Evaluation of Carcinogenic Risks to Humans. Vol 83, Tobacco Smoke and Involuntary Smoking; Lyon, France: France International Agency for Research on Cancer; 2004. Available from: http://monographs.iarc.fr/ENG/Monographs/vol83/ index.php. Accessed February 2, 2017.

38. Dossus L, Boutron-Ruault MC, Kaaks R, et al. Active and passive cigarette smoking and breast cancer risk: results from the EPIC cohort. Int J Cancer. 2014;134:1871-1888.

39. IARC. IARC Monographs on the Evaluation of Carcinogenic Risks to Humans. Vol 100E, Personal Habits and Indoor Combustions. International Agency for Research on Cancer; 2012. Available from: http://monographs. iarc.fr/ENG/Monographs/vol100E/. Accessed February 2, 2017.
40. Gross CP, Filardo G, Singh HS, Freedman AN, Farrell MH. The relation between projected breast cancer risk, perceived cancer risk, and mammography use. Results from the national health interview survey. J Gen Intern Med. 2006;21(2):158-164.

41. Petrakis NL, Gruenke LD, Beelen TC, Castagnoli N, Craig JC. Nicotine in breast fluid of nonlactating women. Science. 1978;199:303-305.

42. Thompson PA, DeMarini DM, Kadlubar FF, et al. Evidence for the presence of mutagenic arylamines in human breast milk and DNA adducts in exfoliated breast ductal epithelial cells. Environ Mol Mutagen. 2002;39(2-3):134-142.

43. Hecht SS: Tobacco smoke carcinogens and breast cancer. Environ Mol Mutagen. 2002;39(2-3):119-126.

44. Di Cello F, Flowers VL, Li H, et al. Cigarette smoke induces epithelial to mesenchymal transition and increases the metastatic ability of breast cancer cells. Mol Cancer. 2013;12:90.

45. Kalluri R, Weinberg RA. The basics of epithelial-mesenchymal transition. J Clin Invest. 2009;119(6):1420-1428.

46. Kispert SE, Marentette JO, McHowat J. Enhanced breast cancer cell adherence to the lung endothelium via PAF acetylhydrolase inhibition: a potential mechanism for enhanced metastasis in smokers. Am JPhysiol Cell Physiol. 2014;307(10):C951-C956.

47. Slattery ML, Lundgreen A, Hines LM, et al. Genetic variation in the JAK/STAT/SOCS signaling pathway influences breast cancer-specific mortality through interaction with cigarette smoking and use of aspirin/ NSAIDs: The Breast Cancer Health Disparities Study. Breast Cancer Res Treat. 2014;147(1):145-158.

48. Kasajova P, Holubekova V, Mendelova A, et al. Active cigarette smoking and the risk of breast cancer at the level of $\mathrm{N}$-acetyltransferase 2 (NAT2) gene polymorphisms. Tumour Biol. 2016;37(6):7929-7937.

49. Morabia A, Bernstein MS, Bouchardy I, Kurtz J, Morris MA. Breast cancer and active and passive smoking: the role of the $\mathrm{N}$-acetyltransferase 2 genotype. Am J Epidemiol. 2000;152(3):226-232.

50. Zheng W, Deitz AC, Campbell DR, et al. N-acetyltransferase 1 genetic polymorphism, cigarette smoking, well-done meat intake, and breast cancer risk. Cancer Epidemiol Biomarkers Prev. 1999;8(3):233-239.

51. Hein DW. Acetylator genotype and arylamine-induced carcinogenesis. Biochim Biophys Acta. 1988;948(1):37-66.
Breast Cancer - Targets and Therapy

\section{Publish your work in this journal}

Breast Cancer - Targets and Therapy is an international, peerreviewed open access journal focusing on breast cancer research, identification of therapeutic targets and the optimal use of preventative and integrated treatment interventions to achieve improved outcomes, enhanced survival and quality of life for the cancer patient.

\section{Dovepress}

The manuscript management system is completely online and includes a very quick and fair peer-review system, which is all easy to use. Visit http://www.dovepress.com/testimonials.php to read real quotes from published authors. 